\title{
Valorisation of brewers' spent grain in different particle size in yogurt production
}

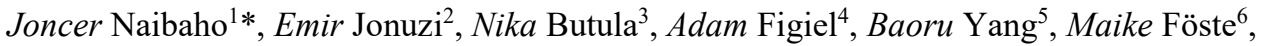 \\ Oskar Laaksonen ${ }^{5}$, Mary-Liis Kütt ${ }^{7}$, and Małgorzata Korzeniowska ${ }^{1}$
}

${ }^{1}$ Department of Functional Food Products Development, Faculty of Biotechnology and Food Science, Wroclaw University of Environmental and Life Sciences, 51-630, Wroclaw, Poland

${ }^{2}$ Department of Chemistry, Faculty of Natural Sciences and Mathematics, University of Tetova, 1200 Tetovo, North Macedonia

${ }^{3}$ Department of Food Engineering, Faculty of Food Technology and Biotechnology, University of Zagreb, Zagreb 10000, Croatia

${ }^{4}$ Institute of Agricultural Engineering, Wroclaw University of Environmental and Life Sciences, 51630, Wroclaw, Poland

${ }^{5}$ Food Chemistry and Food Development, Department of Life Technologies, University of Turku, 20014 Turku, Finland

${ }^{6}$ Fraunhofer Institute for Process Engineering and Packaging IVV, 85354 Freising, Germany

${ }^{7}$ Center of Food and Fermentation Technologies, TFTAK, 12618 Tallim, Estonia

\begin{abstract}
The potential of brewers' spent grain (BSG) as a functional food ingredient has been investigated for having high nutritional value. A high amount of dietary fiber of BSG shows a high ability to bind water; thus, it tends to solidify food mixture. This characteristic has a beneficial effect in the utilization of BSG as a filler and texturizer in yogurt. The study aims to evaluate the impact of the BSG addition in yogurt production and its quality. BSG was prepared in three different particle sizes, and an amount of $10 \%$ was added for yogurt fermentation. The impact of BSG addition was evaluated after $24 \mathrm{~h}$ of storage. The result shows that different particle sizes of BSG had no significant impact on $\mathrm{pH}$ and syneresis, while it significantly affected the amount of lactic acid and countable S. thermophilus. However, BSG increased the fermentation rate of yogurt, and had a positive impact on water holding capacity. A lower particle size had a higher amount of lactic acid and a lower $S$. thermophilus. The lower particle size lowered the lightness of the yogurt. Rheological analysis showed that a higher particle size of BSG increased the shear stress and viscosity of yogurt.
\end{abstract}

\section{Introduction}

A byproduct of the brewery industry called BSG (brewers' spent grain) [1] has been used as animal feed and fertilizer [2,3]. However, several studies have identified the potential of BSG in generating a higher value added [4-8]. Dried BSG approximately contains $2.7-5 \%$

\footnotetext{
* Corresponding author: joncer.naibaho@upwr.edu.pl
} 
ash content, $14.5-30 \%$ crude protein, $0.43-2.17 \%$ starch, and $8-30.8 \%$ extracted fat [9-12]. BSG possesses biological activities, including antimicrobial activity, antioxidant activity, DNA protection, and antimutagenic activities, maintaining colon health and antiinflammatory.

Bioactive substances such as polyphenols, fatty acids, amino acids, and dietary fiber contribute to these properties. [5].

Dietary fiber plays an important rule in food texture profile. BSG consists of $36 \%$ $58.2 \%$ insoluble dietary fiber (IDF) and only $1.3 \%-9.7 \%$ is soluble dietary fiber (SDF) $[11,13]$. IDF regulates the rigidness, thus increasing the hardness of food products, while SDF maintains softness and food stabilisation [14]. In other words, because BSG has a tendency to harden food, it's crucial to emphasize its potential as a food texturizer and functional food ingredient.

An increase in worldwide market value of yogurt has been observed previously which reported an increase from 38.7 billion USD in 2018 to reach 51.2 USD in 2024 [15]. According to an excellent review [16], study about popularizing yogurt is increasingly rising due to its health benefits and acceptability. The quality of yogurt can be improved by the addition of other ingredients [16]. Therefore, the potential of BSG as a yogurt ingredient is seemingly challenging. Besides the fact that BSG contains high nutritional value, it also maintained rheological behavior, syneresis, lactic acid generation, and lactic acid bacteria growth as well as regulating microstructural characteristics in yogurt during storage [17]. The addition of the phenolic extract of BSG in yogurt is reported for improving the antioxidant and anti-inflammatory of yogurt [18].

Based on many references, the addition of whole BSG in yogurt with different particle sizes has never been reported. A smaller particle size of BSG had a higher bulk density [12]. The difference in particle size might be related to the amount of dietary fiber composition [19]. As a result, BSG's ability to hold water and oil is influenced. Furthermore, particle reduction might generate a brighter color [20]. Therefore, the study aimed to evaluate the influence of the variability in particle size of BSG in yogurt fermentation and quality.

\section{Materials and methods}

\subsection{Materials and BSG preparation}

Preparation of BSG was done following Joncer et al. [21] with some modifications. Dried BSG were ground and sieved in three different particle sizes, $150 \mu \mathrm{m}, 250 \mu \mathrm{m}$, and 385 $\mu \mathrm{m}$, using laboratory scale sieving. The BSG powder then is stored inside aluminium foil bags and maintained in a cold room. Commercial pasteurized milk (fat content 3.2\%) was obtained from the local market. Microbial starter was obtained from the local market. M-17 agar was purchased from Merck, Germany.

\subsection{Yogurt preparation}

A BSG sample was mixed into the milk at a ratio 1:9 (BSG:milk; w/w) based on our previous study and then mixed properly. Yogurt was prepared following the instruction of the microbial starter. Briefly, the formulated mixtures were heated at $90{ }^{\circ} \mathrm{C}$ for 15 minutes, followed by cooling down to $43^{\circ} \mathrm{C}$. Then, the microbial starter was added $(0.05 \mathrm{~g})$ into 100 $\mathrm{g}$ of the mixture. The mixture then was incubated at $43{ }^{\circ} \mathrm{C}$ to reach $\mathrm{pH} 4.5-4.7$ as described [22]. The yogurt was removed into cups for storage at $4{ }^{\circ} \mathrm{C}$. Finally, the yogurt was analyzed after $24 \mathrm{~h}$ of storage with minimum duplicate repetition. 


\subsection{Acidity profile: $\mathrm{pH}$ and production of lactic acid}

The acidity and $\mathrm{pH}$ of yogurt were measured as described [17,22] with a slight modification. The $\mathrm{pH}$ was carried out using an InoLab $\mathrm{pH}$-meter according to the instrument's instructions. Acidity analysis was performed by titration methods by $0.25 \mathrm{M}$ $\mathrm{NaOH}$ for $50 \mathrm{~mL}$ of yogurt by using phenolphthalein's indicator. The acidity is performed in the percentage of lactic acid as is shown in equation 1 [23].

$$
\text { Lactic acid }(\%)=\frac{\text { volume of } \mathrm{NaOH}(\mathrm{mL}) \times \mathrm{N} \times 90}{\text { Samvle } \times 1000} \times 100
$$

\subsection{Microbiological analysis}

Streptococcus thermophilus was counted following ISO 7889/IDF 1172003 by using selected media M-17 (Merck) [22]. The bacteria were grown by deep-plate methods. Streptococci were incubated at $37{ }^{\circ} \mathrm{C}$ for 48 hours. The number of bacteria was estimated and presented in a $\log \mathrm{CFU} / \mathrm{g}$ sample.

\subsection{Analysis of rheological behaviour}

Rhelogical behaviour measurements of yogurt were done using a 6000-rotational Haake RheoStress rheometer, equipped with a thermostatic bath model Haake A10 and a UTM Controller (Thermo Electron GmbH, Karlsruhe, Germany). The assesments were run using a plate, type cone C60/1॰ Ti L no.222-1868/ stainless steel plate (TMP 60 no.222-1891) in a geometry system (gap of $1 \mathrm{~mm}$ ). Before taken to the analysis, yogurt samples were kept for $30 \mathrm{~min}$ at room temperature. Then, a $\mathrm{mL}$ yogurt was applied to the plate for measurement. The viscosity is presented in centipoises (cPs), shear rate is determined in a range of $0-1000 \mathrm{~s}^{-1}$ for $3 \mathrm{~min}[17,22,24]$.

\subsection{Color measurement}

Color performence was analysed using Minolta Chrima Meter CR-400 (Minolta Co.,Ltd., Japan) as described [17]. The calibration was conducted with a white board supplied by the manufacturer. $L^{*}$ describes lightness, $a^{*}$ and $b^{*}$ presents redness to greenness and yellowness to blueness respectively.

\subsection{Syneresis}

Syneresis measurement was carried out as follows. $5 \mathrm{~g}$ of yogurt was centrifuged (4500 $\mathrm{rpm}$; $15 \mathrm{~min} ; 10^{\circ} \mathrm{C}$ ) followed by weighting of the supernatant. The syneresis was calculated as in equation $2[17,25,26]$.

$$
\text { Syneresis }(\%)=\frac{\text { Weight of supernatant }(g)}{\text { Weiaht of voaurt }(a)} \times 100
$$




\subsection{Data analysis}

The data analysis was conducted by analysis of variance (ANOVA) using Statistica software version 13.5.0.17 (TIBCO, Palo Alto, CA, USA) in one-way ANOVA to determine the mean and standard deviation. A significant difference was determined by Tukey HSD post-hoc test at $\mathrm{p}<0.05$ ).

\section{Results and discussion}

\subsection{Fermentation time}

The addition of BSG in three different particle sizes generated the same fermentation time and $\mathrm{pH}$, as can be seen in Table 1. A previous study showed that the addition of BSG increased the fermentation rate in yogurt production [17]. In this study, $\mathrm{pH}(4.5-4.7)$ is reached after $3.5 \mathrm{~h}$ fermentation. According to our previous study [17], fermentation of BSG-added yogurt after $3 \mathrm{~h}$ reached $\mathrm{pH}$ between 4.8-5.0 and after $4 \mathrm{~h}$ reached the $\mathrm{pH}$ between 4.2-4.3. Compared to other studies, BSG increased the fermentation rate. The addition of plant extracts increased the yogurt fermentation period. The addition of plant based ingredients such as sea buckthorn mousse, moringa leaf powder and other anthocyanin-rich increased the fermentation rate $(6-8 \mathrm{~h})$ to reach $\mathrm{pH} 4.5-4.6$ [23].

The decrease in fermentation time has been observed due to the addition of bacteria in yogurt fermentation [27]. This phenomenon is predicted due to proteolytic action which releases the amino acids thus improves microbial growth and contributes to the acidification. In addition, high protein yogurt is reported for having a lower fermentation time [27]. By this, BSG might provide amino acids which are beneficial for microbial growth in yogurt during fermentation. Furthermore, the addition of fat replacers in yogurt reduces the fermentation time in yogurt making [28,29].

Table 1. The impact of BSG in the fermentation process of yogurt.

\begin{tabular}{|c|c|c|}
\hline Particle size of BSG $(\mu \mathrm{m})$ & 1 hour & 3.5 hours \\
\hline$\leq 150$ & 5.67 & 4.45 \\
\hline$\leq 250$ & 5.67 & 4.49 \\
\hline$\leq 385$ & 5.67 & 4.53 \\
\hline
\end{tabular}

\subsection{The impact of BSG in pH, lactic acids and the number of Streptococcus thermophilus of yogurt}

The impact of particle size of BSG in BSG-added yogurt on $\mathrm{pH}$, lactic acid and Streptococcus thermophilus is shown in Table 2. The particle size of BSG had no significant difference $(\mathrm{p} \geq 0.05)$ in $\mathrm{pH}$ of the yogurt after 1 day of storage. A smaller particle size of BSG generated a higher amount of lactic acid in yogurt, even though there was no significant difference $(\mathrm{p} \geq 0.05)$ in particle size $\leq 250 \mu \mathrm{m}$ and $\leq 385 \mu \mathrm{m}$ and the higher amount of lactic acid was generated at a lower $\mathrm{pH}$.

In this study, there is a slight increase in $\mathrm{pH}$ after 1 day of storage. This phenomenon is in contradiction with other studies which observed a decline in $\mathrm{pH}$ at 1 day of storage [26]. Compared to control (data is not shown), the addition of BSG increased the $\mathrm{pH}$ while in other studies, the addition of plant extracts tends to decrease the $\mathrm{pH}$ of yogurt, thus increasing the acidity [26,27]. The amount of lactic acid in BSG-added yogurt with particle size $\leq 150 \mu \mathrm{m}$ aligns with other studies which vary between $0.8-0.9 \%$ [23,27,28]. A higher 
lactic acid can be obtained in high protein yogurt up to $1.0 \%$ [27]. However, a lower lactic acid amount was observed in the addition of some plant extracts which generated below $0.8 \%$ [23]. Lactic acid forming ability in yogurt is influenced by the amount of protein, dry matter, phosphate, lactate, citrate, and minerals [30]. By this, a lower particle size of BSG might provide more protein than that in higher particle size thus generating higher lactic acid. The reduction in the particle of BSG has been reported for improving the properties of BSG by debranching and depolymerization [31,32], therefore releasing entrapped protein [33] which improves the amount of lactic acid in yogurt production.

A variability in the amount of countable $S$. thermophilus was observed as a result of different particle sizes of BSG. Statistical analysis showed that the amount of countable $S$. thermophilus was significantly different $(\mathrm{p}<0.05)$ to each other. Yogurt with the lowest particle size had a lowest number of $S$. thermophilus while it contained the highest amount of lactic acid. This data shows that the lowest particle size of BSG might have a higher growth of Lactobacillus bulgaricus, which was not evaluated in this study. The number of S. thermophilus in this study aligns with the previous studies (7.0-9.5 $\log$ CFU/mL), which involved plant-based ingredients in yogurt [22,26,30].

Table 2. The impact of BSG in different particle size in fermentation and microbial properties of yogurt

\begin{tabular}{|c|c|c|c|}
\hline $\begin{array}{c}\text { Particle size of BSG } \\
(\mu \mathrm{m})\end{array}$ & $\mathrm{pH}$ & Lactic acid (\%) & $\begin{array}{c}\text { Streptococcus thermophilus }(\log \\
\text { CFU } / \mathrm{mL})\end{array}$ \\
\hline$\leq 150$ & $4.67 \pm 0.00^{\mathrm{a}}$ & $0.892 \pm 0.01^{\mathrm{a}}$ & $8.526 \pm 0.02^{\mathrm{c}}$ \\
\hline$\leq 250$ & $4.68 \pm 0.00^{\mathrm{a}}$ & $0.783 \pm 0.04^{\mathrm{b}}$ & $8.707 \pm 0.01^{\mathrm{a}}$ \\
\hline$\leq 385$ & $4.69 \pm 0.00^{\mathrm{a}}$ & $0.717 \pm 0.04^{\mathrm{b}}$ & $8.647 \pm 0.01^{\mathrm{b}}$ \\
\hline
\end{tabular}

Note: Letters in the same column show significant differences from other groups $(\mathrm{p}<0.05)$.

\subsection{Physical properties of BSG-added yogurt}

\subsubsection{Rheological behaviour}

Rheological behaviour of BSG-added yogurt is shown in Figure 1 and Figure 2. The data shows that the lower the particle size, the lower the shear stress and viscosity of yogurt. The viscosity of yogurt decreased with the increase in shear rate shows pseudoplastic and behaviour. The same phenomenon has been observed by previous studies in yogurt $[23,24]$.

\subsubsection{Syneresis}

Impact of BSG in syneresis is presented in Table 3. Statistical analysis on syneresis of BSG-added yogurt shows that particle size had no significant $(p>0.05)$ impact in the syneresis of yogurt. The syneresis of the yogurt in this study varied between $28.02-33.26 \%$. Compared to other studies, the addition of BSG generated a lower syneresis in yogurt. BSG is able to bind more water [12] thus reducing the syneresis in yogurt. The addition of plant seed mucilage in yogurt had syneresis at a range $70-80 \%$ which was described as water holding capacity [28], a plant based extract in yogurt generated a range of $35-50 \%$ of 
syneresis [25] and the addition of stabilizer in yogurt had a range of $39-55 \%$ of syneresis in yogurt [25].

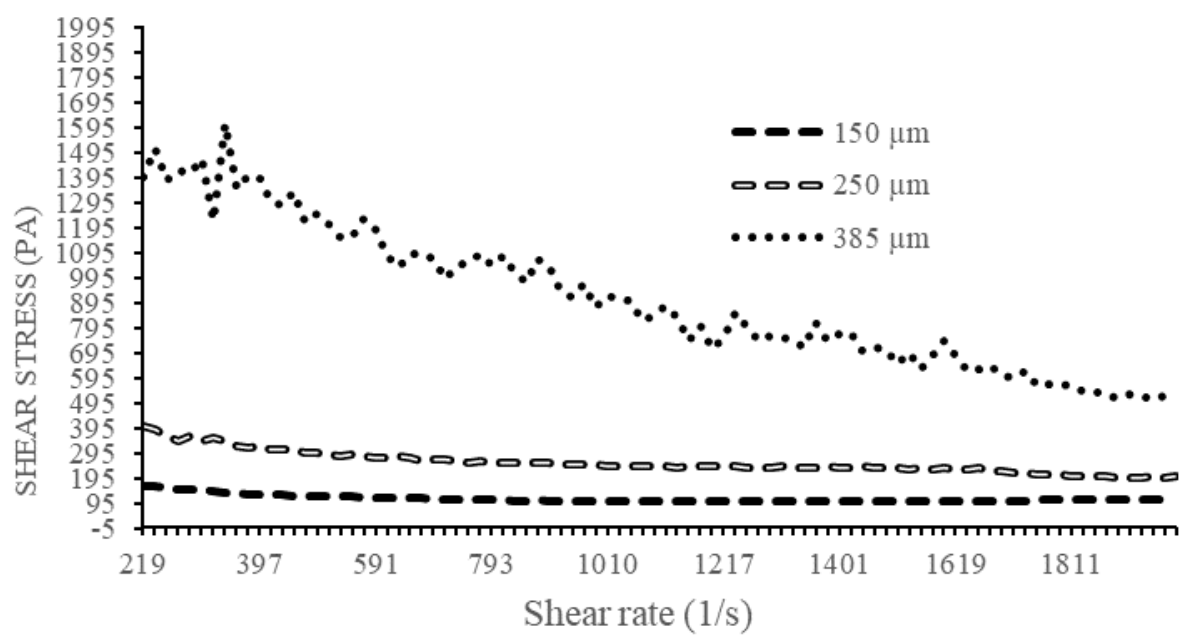

Fig. 1. The shear rate of yogurt with the different particle size of BSG

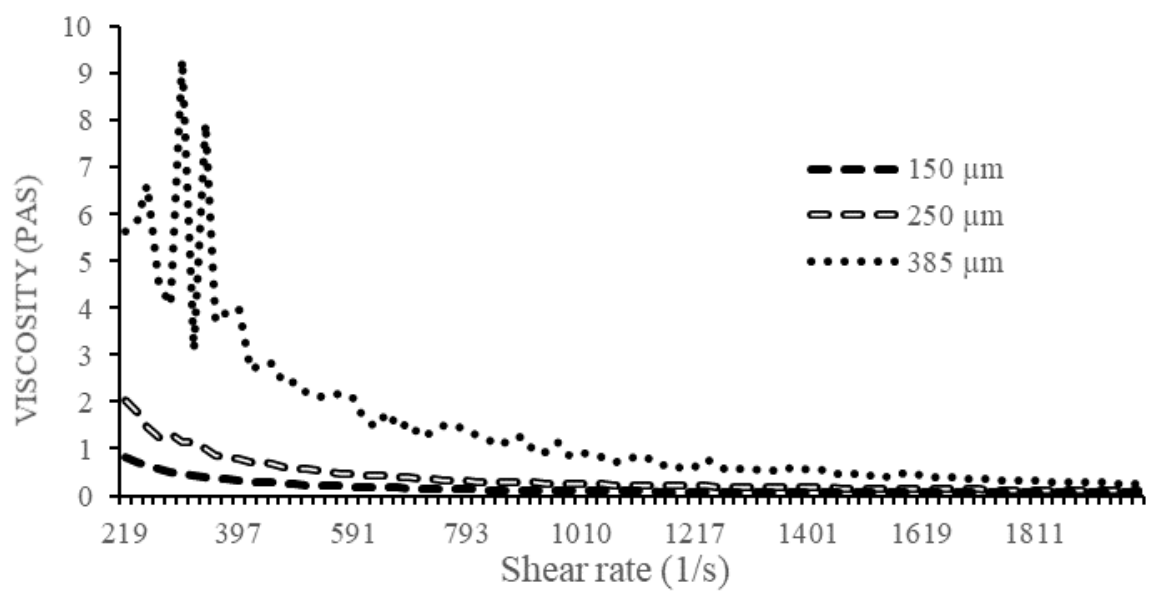

Fig. 2. The impact of the particle size of BSG in viscosity of yogurt

Table 3. The impact of BSG in different particle size in physical properties of yogurt

\begin{tabular}{|c|c|c|c|c|}
\hline \multirow{2}{*}{$\begin{array}{c}\text { Particle size } \\
(\mu \mathrm{m})\end{array}$} & \multicolumn{3}{|c|}{ Color } & \multirow{2}{*}{ Syneresis (\%) } \\
\cline { 2 - 5 } & $\mathrm{L}$ & $\mathrm{a}^{*}$ & $\mathrm{~b}^{*}$ & \\
\hline$\leq 150$ & $66.550 \pm 0.34^{\mathrm{c}}$ & $3.245 \pm 0.16^{\mathrm{a}}$ & $14.770 \pm 0.04^{\mathrm{a}}$ & $29.329 \pm 2.63^{\mathrm{a}}$ \\
\hline$\leq 250$ & $68.050 \pm 0.06^{\mathrm{b}}$ & $2.540 \pm 0.17^{\mathrm{b}}$ & $13.115 \pm 0.23^{\mathrm{b}}$ & $28.020 \pm 1.04^{\mathrm{a}}$ \\
\hline$\leq 385$ & $69.260 \pm 0.04^{\mathrm{a}}$ & $2.610 \pm 0.06^{\mathrm{b}}$ & $12.450 \pm 0.49^{\mathrm{b}}$ & $33.267 \pm 4.09^{\mathrm{a}}$ \\
\hline
\end{tabular}

Note: Letters in the same column show significant differences from other treatments $(p<0.05)$. 


\subsubsection{The color measurement}

Color value of BSG-added yogurt is presented in Table 3. Particle sizes of BSG impacted the color value of the yogurt significantly $(p<0.05)$. The smaller the particle of BSG the lower the lightness of produced yogurt. This phenomenon might be due to the solubility level of BSG. A smaller particle of BSG tends to have higher water solubility, including the solubility of the dietary fiber [31-33] thus darkening the color of the yogurt. The tendency of BSG in reducing the lightness of food products has been reviewed previously [5]. BSG has a brown unique color which could have a beneficial effect in food preferences which can be associated with a healthier product. However, consumer preferences for such products still need to be clarified.

\section{Conclusion}

This study demonstrates the potential of BSG as a food ingredient in yogurt products. BSG addition in yogurt fermentation allows the microbial growth, increases the fermentation rate, and generates a high level of lactic acid. BSG increases the viscosity of the yogurt depending on the particle size of BSG. Therefore, the addition of BSG in yogurt fermentation regulates the rheological behaviour of the yogurt. Moreover, BSG addition in yogurt reduces the syneresis. Particle size at $\leq 150 \mu \mathrm{m}$ revealed a better behavior. Further study in Lactobacillus growth and other biological activities of BSG-added yogurt are needed.

UPWR 2.0, international and interdisciplinary development programme of Wrocaw University of Environmental and Life Sciences supported this project and it was co-funded by the European Social Fund as part of the Operational Programme Knowledge Education Development 2014-2020 : Axis III Higher education for the economy and development; Action 3.5 Comprehensive programmes for schools of higher education (POWR.03.05.00-00-Z062/18).

ERa-NET CO-FUND Horyzont 2020-FACCE SURPLUS Sustainable, and Resilient Agriculture for Food and Non-Food Systems and PROWASTE Protein-fibre biorefinery for scattered material streams (2019-2021) also contributed to the project.

\section{References}

1. G. Garcia-Garcia, J. Stone, and S. Rahimifard, J Clean Prod 211, 1339 (2019)

2. E. J. Lao, N. Dimoso, J. Raymond, and E. R. Mbega, Trop Anim Health Prod 52, 461 (2020)

3. A. Skendi, J. Harasym, and C. M. Galanakis, in Sustainable Recovery and

Reutilization of Cereal Processing By-Products (Elsevier, 2018), pp. 189-225

4. P. S. Nigam, Waste Manag 62, 255 (2017)

5. J. Naibaho and M. Korzeniowska, Journal of Food Science 86, 1532 (2021)

6. S. Wierzba, M. Rajfur, M. Nabrdalik, and A. Kłos, Microchemical Journal 145, 196 (2019)

7. M. Čater, L. Fanedl, Š. Malovrh, and R. Marinšek Logar, Bioresource Technology 186, 261 (2015)

8. M.-A. Berthet, H. Angellier-Coussy, D. Machado, L. Hilliou, A. Staebler, A. Vicente, and N. Gontard, Industrial Crops and Products 69, 110 (2015) 
9. A. O. Balogun, F. Sotoudehniakarani, and A. G. McDonald, Journal of Analytical and Applied Pyrolysis 127, 8 (2017)

10. S. T. Cooray and W. N. Chen, Journal of Functional Foods 42, 85 (2018)

11. F. Nocente, F. Taddei, E. Galassi, and L. Gazza, LWT 114, 108421 (2019)

12. J. Naibaho and M. Korzeniowska, Heliyon 7, e06583 (2021)

13. J. Naibaho, M. Korzeniowska, A. Wojdyło, A. Figiel, B. Yang, O. Laaksonen, M. Föste, R. Vilu, and E. Viiard, Proceedings 70, 6 (2021)

14. M. Föste, C. Verheyen, M. Jekle, and T. Becker, Food Chemistry 306, 125451 (2020)

15. M. Shahbandeh, Forecasted Market Value of Yogurt Worldwide from 2018 to 2024 (2020)

16. N. M. Meybodi, A. M. Mortazavian, M. Arab, and A. Nematollahi, International Dairy Journal 109, 104793 (2020)

17. J. Naibaho, N. Butula, E. Jonuzi, M. Korzeniowska, O. Laaksonen, M. Föste, M.-L. Kütt, and B. Yang, Food Hydrocolloids 107412 (2021)

18. A. L. McCarthy, Y. C. O’Callaghan, A. Connolly, C. O. Piggott, R. J. FitzGerald, and N. M. O'Brien, International Journal of Food Sciences and Nutrition 66, 230 (2015)

19. A. Angioloni and C. Collar, LWT - Food Science and Technology 44, 747 (2011)

20. F. Zucco, Y. Borsuk, and S. D. Arntfield, LWT - Food Science and Technology 44, 2070 (2011)

21. J. Naibaho, M. Korzeniowska, A. Wojdyło, A. Figiel, B. Yang, O. Laaksonen, M. Foste, R. Vilu, and E. Viiard, LWT 149, 111877 (2021)

22. M. Szołtysik, A. Z. Kucharska, A. Sokół-Łętowska, A. Dąbrowska, Ł. Bobak, and J. Chrzanowska, Foods 9, 1167 (2020)

23. N. P. Minh, Plant Sci. Today 8, (2021)

24. T. Huang, Z. Tu, X. Shangguan, H. Wang, L. Zhang, and N. Bansal, Food Chemistry 343, 128413 (2021)

25. S. Khubber, K. Chaturvedi, N. Thakur, N. Sharma, and S. K. Yadav, Food Hydrocolloids 111, 106240 (2021)

26. M. A. Bouaziz, B. Bchir, H. Chalbi, H. Sebii, S. Karra, S. Smaoui, H. Attia, and S. Besbes, Food Measure 15, 309 (2021)

27. F. G. Cavalheiro, D. Parra Baptista, B. Domingues Galli, F. Negrão, M. Nogueira Eberlin, and M. Lúcia Gigante, Food Chemistry 333, 127482 (2020)

28. S. Z. M. Choobari, A. A. Sari, and A. Daraei Garmakhany, Food Sci Nutr 9, 1040 (2021)

29. S. Kokabi, M. Soltani, S. Dabirian, A. Kokabian, A. Daraei Garmakhany, S. Jafarzadeh, and N. Aghajani, Food Sci Nutr 9, 331 (2021)

30. Z. Gürbüz, T. Erkaya-Kotan, and M. Şengül, International Dairy Journal 114, 104938 (2021)

31. C. Severini, D. Azzollini, K. Jouppila, L. Jussi, A. Derossi, and T. De Pilli, Journal of Cereal Science 65, 162 (2015)

32. S. F. Reis, E. Coelho, M. A. Coimbra, and N. Abu-Ghannam, Ultrasonics Sonochemistry 24, 155 (2015)

33. P. Niemi, D. Martins, J. Buchert, and C. B. Faulds, Bioresource Technology 136, 529 (2013) 